\title{
Interactive comment on "The cumulative effects of forest disturbance and climate variability on baseflow in a large watershed in British Columbia, Canada” by Qiang Li et al.
}

\section{Anonymous Referee \#2}

Received and published: 18 July 2016

1. General comment: In this paper, the authors applied the Budyko based method to analyze the effect of climatic variability and forest disturbance on the annual runoff, and then separate the change of the baseflow from the total change of the annual runoff by using conductivity mass balance method. In general, it's hard to say that this paper has any strong innovation point, since it is just a case study based on two common methods. The authors just consider the influence of climatic variability and forest disturbance on the rainfall-runoff relationship, but ignore the possible variation in the relationship between baseflow and total runoff caused by the forest disturbance. The results of paper are questionable. Leaving aside the lack in the methodological contribution, this paper also has a very bad presentation. I think this paper cannot be 
accepted by this journal.

2. Specific comments: (1) Line 31: " $85.2 \pm 21.5$ ", " $0.22 \pm 0.05$ ". I wonder how the terms 21.5 and 0.05 were calculated. The authors presented neither the calculation method nor the specific meaning of these terms in the paper. The similar issues in other parts of this paper are also obvious. (2) Line 35: What is the specific meaning of forest disturbance? Increase or decrease in forest cover? (3) Section 2: The study watershed in this paper spans USA and Canada, but the authors just consider the watershed part in Canada. The part in USA accounts for a quite large percentage of the total area (more than a quarter). It's unreasonable to ignore this part. (4) Line 128: "630 to 2400". The unit of the elevation should be added. (5) Section 2.2.1: Are the climatic data from the observed data or generated from climate models? (6) Lines 145: The multiplication sign cannot be represented by ' $x$ '. (7) Section 3.1: This sub-section which just gives the data of forest disturbance should not be put in the method section. (8) Line 325: Why the parameter $w$ in the Budyko-type equation is set to be 2? (9) Line 366: The detected breaking point in baseflow is in year 1972, but the most significant change in forest cover occurred in 1991 (see Line 204 in this paper). It seems that the change in baseflow has nothing to do with the forest disturbance. Why? (10) Figures: Why the number of figures in this paper starts from 11? It is inconsistent with the figure number in text. (11) Tables $1 \sim 4$ cannot be found in this paper.

Interactive comment on Hydrol. Earth Syst. Sci. Discuss., doi:10.5194/hess-2016-291, 2016. 